\title{
Silver CD-R based substrate as a SERS active material
}

\author{
Marcelina Binczyk $^{1} \cdot$ Martyna Nowak $^{2} \cdot$ Monika Skrobanska $^{2} \cdot$ Bartosz Tylkowski $^{3}$. \\ Tomasz Runka $^{1} \cdot$ Renata Jastrzab $^{2}$
}

Received: 23 June 2015 / Accepted: 11 December 2015 / Published online: 23 December 2015

(C) The Author(s) 2015. This article is published with open access at Springerlink.com

\begin{abstract}
A silver Compact Disc Recortable (CD-R) based substrate has been proposed as an alternative to silver colloids as active material successfully used in surface-enhanced Raman spectroscopy (SERS). Scanning Electron Microscope (SEM) and Energy-Dispersive X-ray Spectroscopy (EDXS) measurements revealed that silver nanoparticles are present over the entire surface of the uncovered reflective layer of commonly used CD-R. The process of preparation of the CD-R based surface is simple, fast and repeatable. Recorded Raman spectra of $10 \mu \mathrm{M}$ Rhodamine $6 \mathrm{G}$ applied to the substrate corroborate strong enhancement of Raman signal. The maximum value of $\mathrm{EF}$ was calculated to be about $5.76 \times 10^{6}$. Raman maps are consistent with SEM micrographs and confirmed the presence of a numerous SERS hot spots occurring on the trucks of CD-R based substrate.
\end{abstract}

Keywords Nanomaterials · Raman spectroscopy - SERS technique $\cdot$ CD-R surface $\cdot$ Silver nanoparticles

$\begin{array}{ll}\text { Abbreviations } \\ \text { SERS } & \text { Surface-enhanced raman spectroscopy } \\ \text { R6G } & \text { Rhodamine 6G } \\ \text { IUPAC name } & \text { [9-(2-ethoxycarbonylphenyl)-6-(ethylamino)- } \\ & \begin{array}{l}\text { 2,7-dimethylxanthen-3-ylidene]-ethylaza- } \\ \text { nium chloride }\end{array}\end{array}$

Renata Jastrzab

renatad@amu.edu.pl

1 Faculty of Technical Physics, Poznan University of Technology, Piotrowo 3A, 60-965 Poznan, Poland

2 Faculty of Chemistry, Adam Mickiewicz University, Umultowska 89b, 61-614 Poznan, Poland

3 Departament de Enginyeria Química, Universitat Rovira i Virgili, Av. Països Catalans 26, 43007 Tarragona, Spain
CD-R
Compact disc recordable
SEM
EDXS
Scanning electron microscope
Energy-dispersive X-ray spectroscopy

\section{Introduction}

The surface-enhanced Raman spectroscopy (SERS) is an extremely sensitive technique which provides amplification of the Raman signal by several orders of magnitude, thereby allowing the identification and structural characterization of small quantities of species [1-3]. This technique gives a number of additional possible applications, including: detection of single molecules [4-6] and indirect analysis of metallic surface properties [2]. Therefore, the SERS effect has been studied extensively in recent decades.

Among many theories proposed to explain the process of surface enhanced Raman spectroscopy, it is widely accepted that SERS effect consists using the large local field enhancements that can exist on the metallic surface (under the right conditions, typically by profiting from localized surface plasmon resonances) to boost the Raman scattering signal of molecules at (or close to) the surface $[2,6,7]$. Hence, the SERS process, and as a consequence enhancement factor (EF), depend on a number of parameters related not only to the analyte and excitation beam (like in normal Raman) but also on the surface. The chemical structure of the species, concentration and distance from the surface, efficiency of adsorption and possible impact on the Raman cross-section of molecules chemically adsorbed on the surface must be taken into consideration, which give the so-called chemical contribution to SERS EF. On the other hand, the most important contribution to SERS EF is brought by the electromagnetic factor that strongly depends on the properties of laser excitation (wavelength, power 
density, polarization, etc.) and on the kind of metallic structures, their shapes, size, orientation and homogeneity [2, 6, $8,9]$.

Different kinds of SERS active substrates are extensively described in the literature. Mostly silver and gold nanostructures and colloids with dimension less than $100 \mathrm{~nm}$ are used because of their suitable optical properties to sustain plasmon resonances in the visible and near-infrared range [2]. However, in terms of the shape of the structures wide diversity is observed, from metallic colloids in solution to structures like: nanowires [10-12], nanorods [13, 14], nanocomb arrays [15], nanocluster films [16, 17], deserrose-like [18] or dendritic nanostructures [19]. Although a variety of electrochemical, nanolitographic and deposition methods or synthesis have been employed with some success to fabricate SERS [20-25]. It is still in request to produce a low cost effective, reproducible, readily available and easy to manufacture substrate.

In this work new SERS-active substrate based on commercially available silver Compact Disc Recordable (CD$\mathrm{R}$ ) is proposed, as a new hitherto not described in the literature material, which is cheap and easy to obtain.

\section{Experimental}

\section{Preparation of the SERS-active surface}

A standard CD-R is made of polycarbonate plastic blank on the reflective layer (usually aluminium, but sometimes silver or gold). The metal is protected by a film of lacquer, normally spin coated directly on the reflective layer Fig. 1 [26].

CD-R Ultima 80 made by Kodak, with a silver reflexive layer was used for measurements after removing polycarbonate layer. A fragment of the CD-R disc was cut off and the reflexive layer was gently separated from the polycarbonate substrate. The reflexive layer was placed in toluene (MERCK) for 10 min for removing polycarbonate residues. The prepared layer was mounted on a microscopic slide by a double sided adhesive tape and dried on the air. A drop of $10^{-6} \mathrm{M}$ water solution of Rhodamine 6G (R6G) (SigmaAldrich) was deposited on prepared substrate and left to dry on the air. The formula and structure of R6G are shown in Fig. 2. The solution was prepared using fresh deionised carbonate-free water (conductivity below $0.055 \mu \mathrm{S} / \mathrm{cm}$ ).

\section{Microstructure analysis}

SEM-EDXS measurements were performed by Scanning Electron Microscope SEM-FEI Quanta 600 equipped with PentaFETx3 Link Dispersive Energy X-ray Spectroscopy EDXS system managed by IncaOxford. A Si(Li) detector

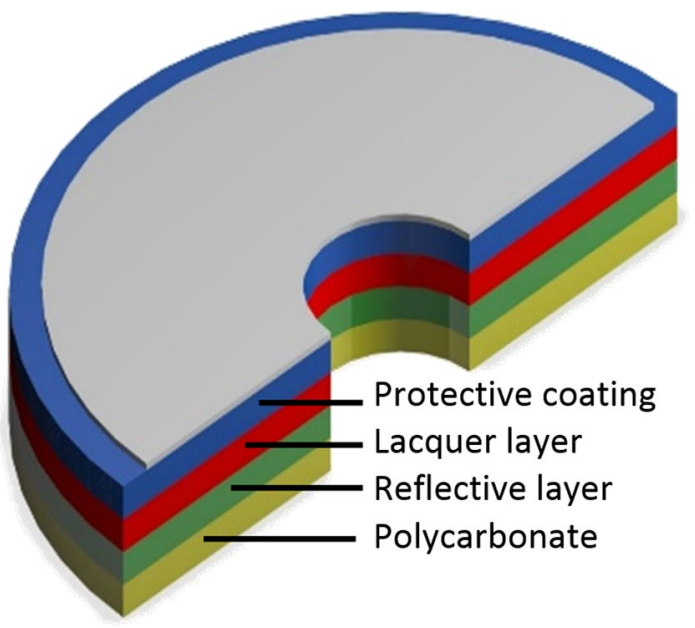

Fig. 1 The CD cross-section
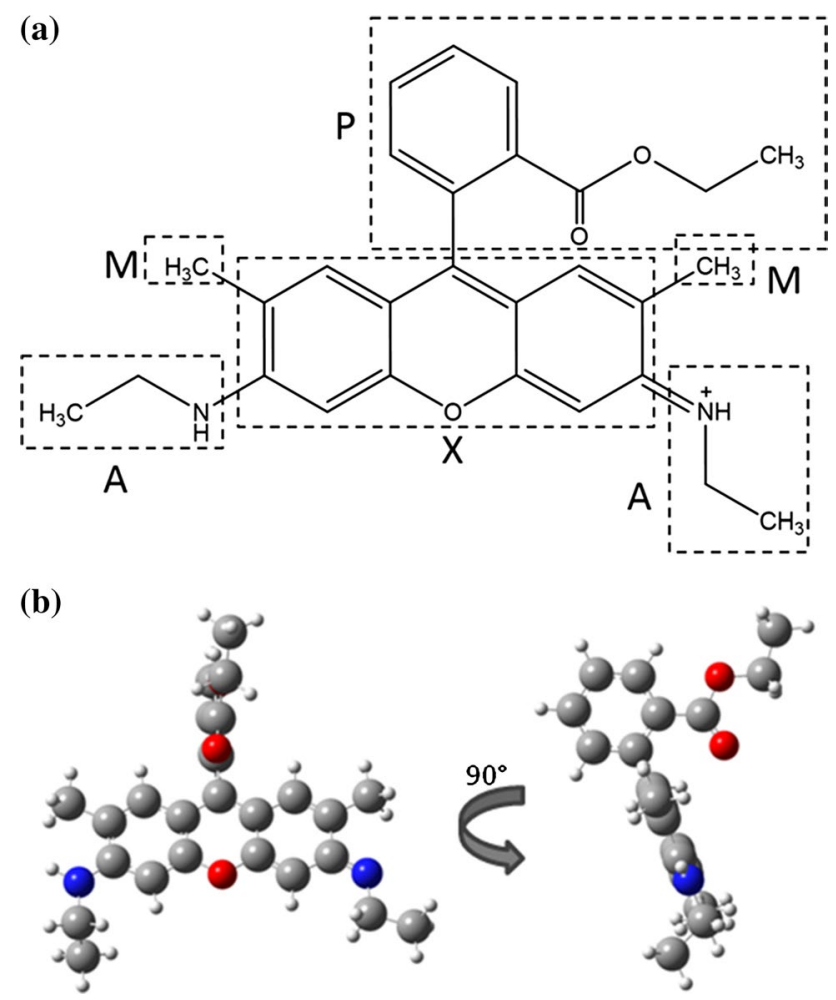

Fig. 2 Formula (a) and structure (b) of Rhodamine 6G (R6G) ( $P$ phenyl ring, $M$ methyl group, $A \mathrm{NHC}_{2} \mathrm{H}_{5}$ group and $X$ xanthene ring)

with a ultra-thin window ATW2, the resolution of $137 \mathrm{eV}$ at $5(\mathrm{MnK} \alpha 1)$. The spectral data were acquired at the working distance $10.6 \mathrm{~mm}$ with an acceleration voltage (AV) of $20 \mathrm{kV}$.

In this work, the minimum required $\mathrm{AV}$ for $\mathrm{CD}-\mathrm{R}$ sample was $6 \mathrm{kV}$, and all spectral data were acquired with counting time of $60 \mathrm{~s}$, count for second approximately 642 
Fig. 3 SEM image of CD-ROM surface recorded with magnification $\mathbf{a} \times 1500, \mathbf{b} \times 20,000$
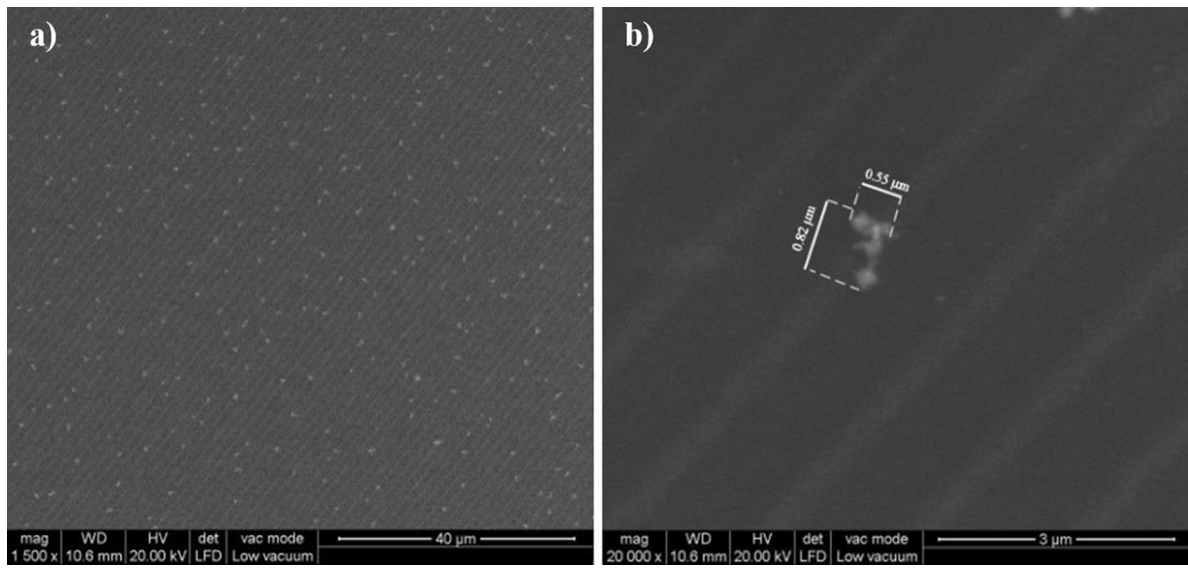

cps with deadtime below $30 \%$. The results were processed by Inca software energy, which uses the XPP matrix correction scheme.

\section{SERS measurements}

All Raman maps and spectra of Rhodamine 6G adsorbed onto CD-R based substrate were recorded using Renishaw inVia Raman microscope equipped with an Argon-ion laser emitting $514.5 \mathrm{~nm}$ wavelength. The laser beam was reduced down to $2 \mu \mathrm{W}$ and was focused on the sample through a long working distance of the $50 \mathrm{x} / \mathrm{NA} 0.5$ objective, thus the spatial resolution was better than $2 \mu \mathrm{m}$. The spectral resolution owing to the spectrometer being equipped with a $1800 \mathrm{~g} / \mathrm{mm}$ diffraction grating was better than $2 \mathrm{~cm}^{-1}$. The position of Raman peaks was calibrated before collecting the data using a Si sample as an internal standard. The Raman spectra of R6G were measured in 70-3200 $\mathrm{cm}^{-1}$ spectral range to correctly identify the dye and then, the spectral range was narrowed down to the 945$1825 \mathrm{~cm}^{-1}$, in order to observe only the bands most characteristic for R6G.

\section{Results and discussion}

The surface characterisation of silver-based CD-R substrate was performed using the SEM/EDXS technique. SEM images of the CD-R surface obtained at room temperature in two different magnifications are presented in Fig. 3. The low magnification image $(1500 \times)$ in Fig. 3a shows a typical surface of CD-R consisting of parallel tracks with a large number of bright dots. As can be observed from the high magnification mocrograph in Fig. $3 b(20,000 \times)$ the tracks are spaced apart by $1.6 \mu \mathrm{m}$ and at the centre of the image an irregular shape of aggregated silver nanostructure of dimensions $0.55 \times 0.82 \mu \mathrm{m}^{2}$ is observed.

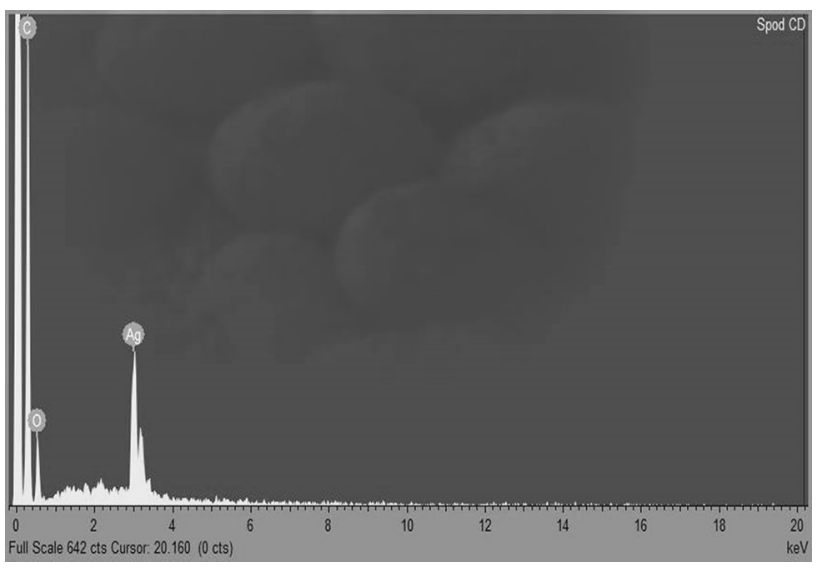

Fig. 4 EDXS spectrum of the white spots (silver particles)

Elemental EDXS spectrum acquired from a single silver particle is presented in Fig. 4. The EDXS spectrum is displayed in digitized form with the $\mathrm{X}$-axis representing X-ray energy and the $y$-axis representing the number of counts per channel. Peaks at 0.277 and $0.525 \mathrm{keV}$ correspond to carbon and oxygen, the elements which make the $\mathrm{CD}-\mathrm{R}$ matrix, while the peak at $2.984 \mathrm{keV}$ is attributed to the silver particles present on this matrix surface. SEM image with EDXS shows that the dark surface background in Fig. 3 is attributed to carbon and the homogenously distributed white spots are attributed to the silver particles. Figure $3 \mathrm{~b}$ showsa single silver particle. The EDXS semiquantitative analysis of 10 different white spots confirmed that the composition of these particles is $97 \pm 1 \%$ silver, Fig. 4. Therefore, the prepared CD-ROM based sample contains silver nanostructures interesting from the SERS point of view.

Rhodamine $6 \mathrm{G}$ has been well-characterized by SERS [27], it was chosen as the model molecule to study the usefulness of CD-ROM-based sample as SERS active material. The enhancement of R6G signal by uncovered silver 


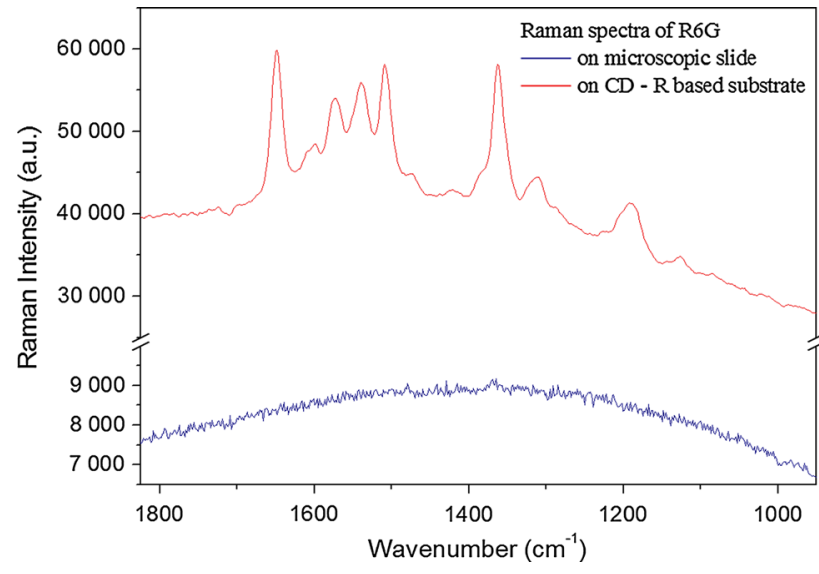

Fig. 5 Raman spectra of Rhodamine 6G

nanoparticles was analysed to define how strong enhancement is it possible to achieve in this composition. Measurements of the Raman map spectra of R6G were realized on area of $20 \times 20 \mu \mathrm{m}^{2}$ with $2 \mu \mathrm{m}$ step size. The spectral range of the SERS mapping experiment was $945-1825 \mathrm{~cm}^{-1}$ and the exposure time $30 \mathrm{~s}$ per point, Fig. 5.

The full assignment of vibrational modes for R6G molecule by high-level density functional theory (DFT) calculations was proposed by Watanabe et al. [27] Rhodamine 6G molecule (Fig. 2) contains several vibrational units that can be described as " $\mathrm{X}$ " which represent the xanthene ring, "A" represents two $\mathrm{NHC}_{2} \mathrm{H}_{5}$ groups, " $\mathrm{M}$ " represents the two methyl groups, and " $\mathrm{P}$ " represents the phenyl ring with $\mathrm{COOC}_{2} \mathrm{H}_{5}$ group [27]. Figure 5b presents four different spectra chosen from the four different points from the area presented in Fig. 5a. The spectrum obtained from point $\mathrm{D}$ shows very low intensity Raman features and is typical for no enhanced signal. The spectra took from points $\mathrm{A}, \mathrm{B}$ and $\mathrm{C}$ clearly exhibit characteristic peaks of R6G molecules at 1363, 1508, 1540, 1575 and $1650 \mathrm{~cm}^{-1}$. The modes recorded at 1363 and $1508 \mathrm{~cm}^{-1}$ are assigned to $\mathrm{C}-\mathrm{C}$ stretching vibration of xanthane ring and $\mathrm{NHC}_{2} \mathrm{H}_{5}$ group. The band recorded at $1540 \mathrm{~cm}^{-1}$ is also attributed to vibrations of " $\mathrm{X}$ " and " $\mathrm{A}$ " part of R6G molecule. The vibrational mode at $1575 \mathrm{~cm}^{-1}$ is localized in the phenyl ring ("P" part) and is caused by $\mathrm{C}=\mathrm{C}$ symmetric stretching. The highest intensity mode located at $1650 \mathrm{~cm}^{-1}$ is assigned to totally symmetric stretching vibrations of $\mathrm{C}=\mathrm{C}$ bond and symmetric in-plane $\mathrm{C}-\mathrm{H}$ bending vibrations of the xanthene ring " $\mathrm{X}$ ". The intensity of all bands changes with the position on the sample, which is correlated with the presence and the size of silver nanostructures on the surface of the CD-ROM-based substrate. In order to show the R6G Raman signal enhancement depending on the silver nanoparticles occurrence, the intensity of the strongest mode corresponding to $\mathrm{C}=\mathrm{C}$ symmetric stretching vibrations of xanthene ring was presented in Fig. 6a. The estimated accuracy of the peak position of the band at $1650 \mathrm{~cm}^{-1}$ is equal to $\pm 1 \mathrm{~cm}^{-1}$ and the change in the band position is not related to calibration of the spectrometer but is a physical effect. To determine correctly the intensity of the mode recorded at $1650 \mathrm{~cm}^{-1}$, the background was cut off. The map of its intensity as a function of $\mathrm{XY}$ position is presented in Fig. 6b.

The hot-spots, where the intensity is much stronger, are not along all tracks, but occur only in some points of the surface. The intensity of the band at $1650 \mathrm{~cm}^{-1}$ at point $\mathrm{A}$ is 5 times stronger than that at point $\mathrm{D}$. Furthermore, the lower intensity Raman spectrum recorded for point D demonstrates Raman features over the fluorescent background. The EF that confirms the efficiency of SERS signal has been estimated using formulae: $\mathrm{EF}=\left(I_{\text {SERS }} / N_{\text {ads }}\right) /\left(I_{\text {bulk }} / N_{\text {bulk }}\right)$, where $I_{\text {SERS }}$ is the intensity of selected vibrational mode in the SERS experiment, $I_{\text {bulk }}$ is the intensity of the same Raman mode in the spectrum recorded for bulk material, $N_{\text {ads }}$ is the number of molecules adsorbed and probed in SERS experiment, and $N_{\text {bulk }}$ is the number of molecules probed in confocal volume of the optical system of Raman experiment [28-30]. The estimated number of R6G molecules on the area of laser spot $N_{\text {ads }}$ assuming close packing is equal to
Fig. 6 R6G Raman mapping a measurement accuracy; b Raman map
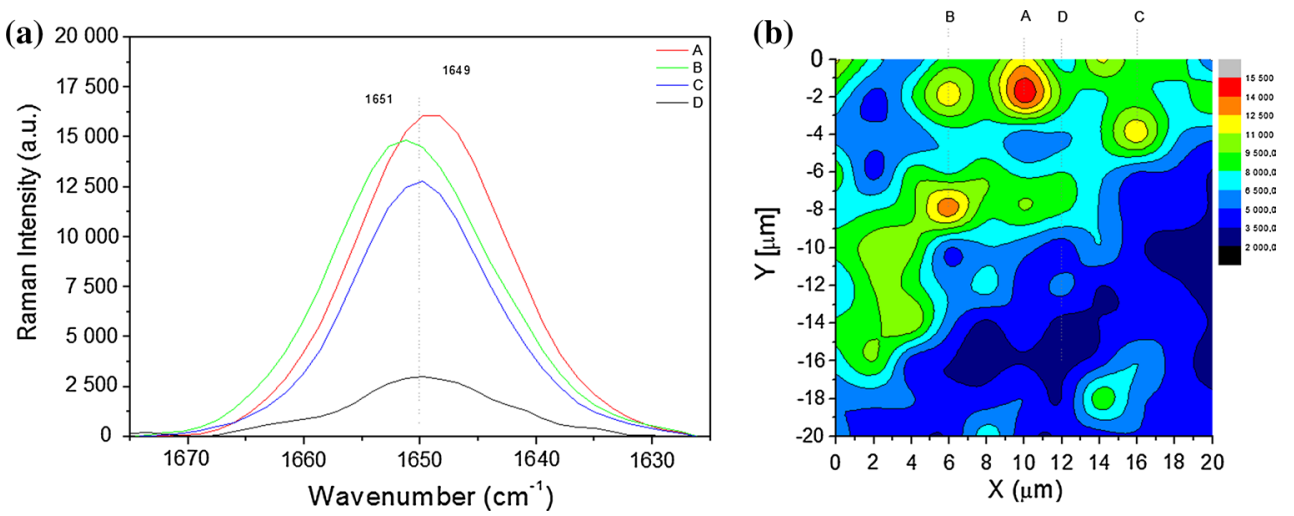
$3.12 \times 10^{5}$, while the number of R6G molecules in the solid state material in the laser illumination volume $N_{\text {bulk }}$ is equal to $19.74 \times 10^{9}$. The intensity $I_{\text {SERS }}$ of the of the Raman band at $1650 \mathrm{~cm}^{-1}$ at point A of Raman map (the strongest SERS signal) was about 16,000 a.u., whereas the intensity $I_{\text {bulk }}$ of the same band recorded for bulk material was 176 a.u. Finally, substituting values of $N_{\text {ads }}$, $N_{\text {bulk }}, I_{\text {SERS }}$ and $I_{\text {bulk }}$ to mentioned above formulae, EF was calculated to be about $5.76 \times 10^{6}$. The value of $\mathrm{EF}$ is quite comparable to values obtained by other Authors for different SERS-active substrates [28-30]. The obtained results proved usefulness of CD-R based substrate containing silver nanostructures for enhancement of Raman signal.

\section{Conclusion}

The results, presented in this work, showed that the layer rich in nanostructures of silver can be easily uncovered after removal of polycarbonate from CD-R. Moreover, the Raman signal of Rhodamine $6 \mathrm{G}$ adsorbed on this uncovered layer was successfully enhanced. The commercially produced CD-R with silver reflective layer was used as a SERS-active material for the first time. The polycarbonate plastic blank was removed and reflective layer was uncovered. In the SEM analysis the silver nanoparticles were lying on the horizontal line in different points of the sample, but always on CD-R trucks. The recorded SERS spectra of low-concentration of Rhodamine 6G show characteristic vibrational modes in the $945-1825 \mathrm{~cm}^{-1}$ spectral range. The Raman maps reveal the hot-spots on the surface where the intensity of detected SERS signal is the strongest and they usually exist on tracks which complies with the SEM micrographs. The estimated EF value for the strongest signal at point $\mathrm{A}$ of Raman map is about $3.45 \times 10^{6}$. It is very important that the preparation process of CD-R based substrate is fast, simple and repeatable.

Acknowledgments This work was supported by the Research Project of the Polish Ministry of Sciences and Higher Education DS/64-414/2014.

Open Access This article is distributed under the terms of the Creative Commons Attribution 4.0 International License (http://creativecommons.org/licenses/by/4.0/), which permits unrestricted use, distribution, and reproduction in any medium, provided you give appropriate credit to the original author(s) and the source, provide a link to the Creative Commons license, and indicate if changes were made.

\section{References}

1. S.E.J. Bell, N.M.S. Sirimuthu, Chem. Soc. Rev. 37, 1012 (2008)

2. E. Le Ru, P. Etchegoin, Elsevier, Amsterdam, Netherlands, Oxford (2009)

3. K. Kneipp, M. Moskovits, H. Kneipp, Springer-Verlag Berlin and Heidelberg GmbH and Co. KG (2009)

4. K. Kneipp, Y. Wang, H. Kneipp, L. Perelman, I. Itzkan, R. Dasari, M.S. Feld, Phys. Rev. Lett. 78, 1667 (1997)

5. P.G. Etchegoin, E.C. Le Ru, Phys. Chem. Chem. Phys. 10, 6079 (2008)

6. S. Schlücker, Angew. Chem. Int. Ed. Engl. 19, 4756 (2014)

7. S. Schlücker, Surface enhanced Raman spectroscopy: analytical, biophysical and life science applications (Wiley-VCH Verlag and Co. KGaA, Weinheim, 2011)

8. J. Kneipp, Top Appl Phys.; 103, 335 (2006)

9. E.C. Le Ru, E. Blackie, M. Meyer, P.G. Etchegoin, J. Phys. Chem. C 111, 13794 (2007)

10. Y. He, S. Su, T. Xu, Y. Zhong, J.A. Zapien, J. Li, C. Fan, S.T. Lee, Nano Today. 6, 122 (2011)

11. X. Yang, H. Zhong, Y. Zhu, J. Shen, C. Li, Dalton Trans. 42, 14324 (2013)

12. L. Chen, J.M. Chabu, R. Jin, J. Xiao, RSC Adv. 3, 26102 (2013)

13. R. Kattumenu, C.H. Lee, L. Tian, M.E. McConney, S. Singamaneni, J. Mater. Chem. 21, 15218 (2011)

14. M.Y. Tsvetkov, B.N. Khlebtsov, V.A. Khanadeev, V.N. Bagratashvili, P.S. Timashev, M.I. Samoylovich, N.G. Khlebtsov, Nanoscale Res. Lett. 8, 250 (2013)

15. Y.J. Liu, Z.Y. Zhang, Q. Zhao, R.A. Dluhy, Y.P. Zhao, Appl. Phys. Lett. 94, 033103 (2009)

16. R. Botta, G. Upender, R. Sathyavathi, D. Narayana Rao, C. Bansal, Mater. Chem. Phys. 137, 699 (2013)

17. J. Leem, H.W. Kang, S.H. Ko, H.J. Sung, Nanoscale. 6, 2895 (2014)

18. H. Schneidewind, T. Schuler, K.K. Strelau, K. Weber, D. Cialla, M. Diegel, R. Matthies, A. Berger, R. Moller, J. Popp, J. Beilstein, Nanotechnol 3, 404 (2012)

19. X. Sun, L. Lin, Z. Li, Z. Zhang, J. Feng, Mater. Lett. 63, 2306 (2009)

20. M. Fan, G.F.S. Andrade, A.G. Brolo, Anal. Chim. Acta 693, 7 (2011)

21. X. Zhang, Q. Zhou, Y. Huang, Z. Li, Z. Zhang, Int. J Spectrosc. 2012, 1 (2012)

22. A. Dhawan, Y. Du, F. Yan, M.D. Gerhold, V. Misra, T. Vo-Dinh, IEEE Sens. J. 10, 608 (2010)

23. G.B. Jung, Y.M. Bae, Y.J. Lee, S.H. Ryu, H.-K. Park, Appl. Surf. Sci. 282, 161 (2013)

24. K.B. Crozier, W. Zhu, D. Wang, S. Lin, M.D. Best, J.P. Camden, IEEE J. Sel. Top. Quantum Electron. 1 (2014)

25. A. Bouvrée, A. D'Orlando, T. Makiabadi, S. Martin, G. Louarn, J.Y. Mevellec, B. Humbert, Gold Bull. 283 (2013)

26. D.C. Kirkpatrick, C. Antwi, R.S. Martin, Anal. Methods 2, 811 (2010)

27. H. Watanabe, N. Hayazawa, Y. Inouye, S. Kawata, J. Phys. Chem. B. 109, 5012 (2005)

28. H. Jia, X. Bai, N. Li, L. Yu, Cryst. Eng. Comm. 13, 6179 (2011)

29. C. Leordean, B. Marta, A.-M. Gaubudean, M. Focsan, I. Botiz, S. Astilean, Appl. Surf. Sci. 349, 190 (2015)

30. C. Leordean, M. Potara, S. Boca-Farcau, A. Vulpoi, S. Astilean, C. Farcau, J. Raman Spectrosc. 45, 627 (2014) 